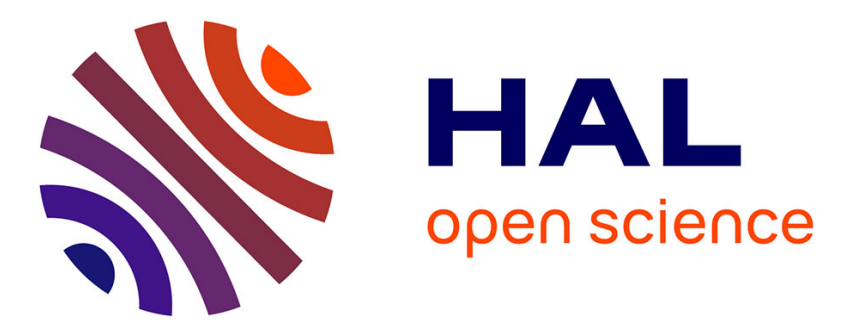

\title{
Chloride transport through cementitious membranes using pulsed current
}

B. Diaz, X.Ramon Novoa, Beatriz Puga, Vincent Vivier

\section{To cite this version:}

B. Diaz, X.Ramon Novoa, Beatriz Puga, Vincent Vivier. Chloride transport through cementitious membranes using pulsed current. Cement and Concrete Composites, 2013, 39, pp.18-22. 10.1016/j.cemconcomp.2013.03.018 . hal-00831477

\section{HAL Id: hal-00831477 \\ https://hal.sorbonne-universite.fr/hal-00831477}

Submitted on 24 Apr 2015

HAL is a multi-disciplinary open access archive for the deposit and dissemination of scientific research documents, whether they are published or not. The documents may come from teaching and research institutions in France or abroad, or from public or private research centers.
L'archive ouverte pluridisciplinaire HAL, est destinée au dépôt et à la diffusion de documents scientifiques de niveau recherche, publiés ou non, émanant des établissements d'enseignement et de recherche français ou étrangers, des laboratoires publics ou privés. 


\title{
Chloride transport through cementitious membranes using pulsed current
}

\author{
B. Díaz ${ }^{a}$, X.R. Nóvoa ${ }^{a}$, B. Puga ${ }^{a}$, V. Vivier ${ }^{b}$ \\ ${ }^{a}$ Grupo ENCOMAT, Universidade de Vigo, EEI, Campus Universitario, Spain, \\ ${ }^{b}$ LISE - UPR 15 du CNRS,-4 place Jussieu, 75252 Paris Cedex 05, France \\ Corresponding author, rnovoa@uvigo.es, +34986812213
}

\section{ABSTRACT}

Microstructural changes and chloride transport in cement pastes are studied under DC current and pulsed electric fields. Impedance Spectroscopy and Ultrasonic Pulse Velocity measurements have been employed for quasi-real time monitoring of changes in the cement paste microstructure. The results show that the electric resistivity and ultrasound velocity (measured at $500 \mathrm{kHz}$ ) are modified during the migration experiments. At the end of test, Mercury Intrusion Porosimetry reveals an important increase in the fraction of gel pores. The experimental results show conduction enhanced through gel pores. The use of pulsed current is presented as an alternative method to minimize the negative effects produced by DC current.

KEYWORDS: migration, pulse current, cement paste, microstructure, gel pores. 


\section{INTRODUCTION}

The main factor responsible of the corrosion of steel embedded in reinforced concrete is the presence of chlorides at the steel-concrete interface level. The penetration of chloride ions through cement-based materials is thus a key aspect in the service life of reinforced concrete structures in chloride-containing environments [1].

The forced migration test is employed as an accelerated and useful method, in order to determine the resistance of concrete to chloride ingress $[2,3]$. However, microstructural changes are caused by the application of electrics fields $[4,5]$, which makes those tests controversial. Therefore, the use of pulsed current is presented in the literature as an alternative method to minimize those problems in the particular case of cathodic protection systems [6, 7]. However, no references have been found in the literature on the use of pulsed current for studying chloride transport in chloride extraction and/or realkalinisation related problems, were DC current is widely employed [8-10], although a number of important unwanted side effects have been reported [11-13].

Studies based on electrochemical impedance analysis of the dielectric characteristics of cement pastes $[4,14]$ have evidenced the presence of several ionic conduction phenomena concurrent in cementitious materials. While percolating conduction occurs above $10 \mathrm{kHz}$, the ionic exchange with the pore solution and pore walls has characteristic frequencies at about $1 \mathrm{kHz}$. Thus, it seems reasonable that tuning the frequency makes possible to act on the different conduction paths either to minimise structural damage and/or to increase the current efficiency.

In this research, the microstructural changes produced in the cement paste are studied when pulsed current is applied in the $100 \mathrm{~Hz}-10 \mathrm{kHz}$ range. The idea behind this choice of frequency range is to study the effect of stirring at the micro-level (pore solution to pore walls) in the macroscopic transport of chlorides. Effects of stirring at the micro-level have already been described in microfluidics [15] and other fields [16].

\section{EXPERIMENTAL}

The cement paste samples were prepared using Portland cement type CEM I 52.5R according to the composition, specifications and conformity criteria of EN 197-1:2000, with a water to cement ratio 
of 0.5 . The water-cement mix were cast in cylindrical moulds of $9 \mathrm{~cm}$ diameter and $20 \mathrm{~cm}$ height, and cured in $100 \% \mathrm{RH}$ chamber for 24 hours. Afterwards, the samples were demoulded and maintained in the same chamber for a minimum of 28 days before starting the measurements. Thus, the pore network has reached about $90 \%$ of development [17] and no significant maturation of the paste due to hydration is expected during the time of the experiments. The cement paste samples were cut into $2.5 \mathrm{~cm}$ thick slices to be used in the permeation experiments. Prior to testing the samples were pre-conditioned following a standardized water saturation procedure [18].

The experimental set-up consisted of a classical permeation cell with two-solution compartments at both sides of the cement sample under test. The geometry of the cell was chosen so that the current flow at the edges was compensated [19]. The upstream (or cathodic) compartment was filled with $1 \mathrm{M}$ sodium chloride solution, containing also sodium hydroxide and potassium hydroxide to $\left[\mathrm{OH}^{-}\right]=0.5 \mathrm{M}$. The downstream (or anodic) compartment was filled with just sodium hydroxide and potassium hydroxide solutions to $\left[\mathrm{OH}^{-}\right]=0.5 \mathrm{M}$. The concentrations for $\mathrm{NaOH}$ and $\mathrm{KOH}$ were chosen in order to avoid decalcification and to approach the pore solutions of the tested concrete. Each electrolyte compartment was a cylinder $200 \mathrm{~cm}^{3}$ in volume, $10 \mathrm{~cm}$ length and 20 $\mathrm{cm}^{2}$ base defined by O-rings. The total electrode spacing is then $22.5 \mathrm{~cm}$. A schematic view of the experimental cell is given in Figure 1.

Figure 1

Two graphite sheets placed at both ends of the cell were used for applying the electric field and for recording the measured impedance spectra.

The specimens were subjected to two regimes, direct current and pulsed current. In both regimes the nominal current density applied was $0.3 \mathrm{~mA} \cdot \mathrm{cm}^{-2}$. As the pulsed current was applied as a square wave of $50 \%$ duty cycle, the imposed current during the "on" time was $0.60 \mathrm{~mA} . \mathrm{cm}^{-2}$ to reach the average $0.3 \mathrm{~mA} . \mathrm{cm}^{-2}$ effective. The investigated frequencies were $0.1,1$ and $10 \mathrm{kHz}$. Three parallel cells of each type were mounted to check reproducibility.

During the migration experiments the samples were periodically tested for electrical and mechanical properties. The evolution of the electrical properties was followed using high frequency impedance measurements between the graphite sheets of the permeation cells. An Agilent 4294A precision impedance analyser was employed for that purpose. The frequency range scanned was from $40 \mathrm{MHz}$ down to $40 \mathrm{~Hz}$ although the upper practical limit was limited to $10 \mathrm{MHz}$ to avoid the 
inductive effects inherent to the experimental arrangement. Each impedance measurement was performed 10 minutes after withdrawal of the corresponding sample from the treatment rack. That waiting time was decided, in preliminary experiments, as the minimum necessary for ionic relaxation that allows obtaining steady impedance plots. The samples were returned to the treatment rack short after the impedance measurements. The total "out-of-rack" time for each sample was about 15 minutes per impedance measurement.

The evolution of the mechanical properties was followed using ultrasound propagation measurements. A PUNDIT ${ }^{\circledR}$ Plus model PC 1006 was employed to measure ultrasound speed. The direct transmission arrangement and a transducer of $0.5 \mathrm{MHz}$ were utilized. Sound waves were emitted/collected in direction normal to the electrical current flux. For this purpose the cylindrical shaped samples were slightly abraded to define small flat surfaces at both ends of a diameter normal to the current flux. These surfaces allowed to easily locating the transducers, emitter and receiver, so that ultrasound tests were performed without removing the samples from the rack.

The interpretation of the electrical and mechanical data obtained during the permeation experiment requires microstructural information that was obtained by mercury intrusion porosimetry (MIP) performed on fresh and tested samples. The porosimeter employed was an Autopore IV 9500 from Micromeritics. This porosimeter allows pore diameter in the range from 5 $\mathrm{nm}$ to $0.9 \mathrm{~mm}$ to be determined.

\section{RESULTS AND DISCUSSION}

\subsection{Evaluation of the Chloride Transport}

The evolution of the chloride concentration in both compartments of the cells was followed during the migration experiments by means of a chloride selective electrode. In Fig. 2 the evolution of the chloride concentration in the downstream compartment for the different types of test is compared. The results at $10 \mathrm{kHz}$ are omitted for simplicity because they are almost coincident with those at 1 $\mathrm{kHz}$. This fact evidences that although the chloride transport is frequency sensitive, only the frequencies matching the characteristic time constant of the ionic exchange with pore walls will be relevant. 
It is worth to notice in Fig. 2 the difference in time lag between the DC and pulsed experiments. That time lag marks the frontier between non-steady-state and steady-state diffusion regimes. While the chloride concentration profile through the cement membrane is fully developed at about 10 days for the $D C$ experiment, it takes 23 days to develop for the $A C$ experiments.

Figure 2

During the migration experiment the charge passed through the membrane is the responsible of pore occupancy by chlorides. As the experimental set-up guarantees equal net current flowing through the membrane, the longer time lag obtained for the pulsed tests compared with the DC regime suggest a dissimilar distribution of the incoming chlorides in the pore network. While the DC regime forces ionic motion straight through the percolating porosity, the pulsed current regimes involve also non-percolating pores, which requires more charge for chlorides to reach the downstream compartment (hence more time for equal current applied). This result is in very good agreement with that obtained by Koleva et al. [20].

After the time lag period the flux of chloride ions through the specimen is roughly constant and corresponds to a so-called steady-state period. The slope (efficiency in transport) is higher for the pulsed regimes, being $1 \mathrm{kHz}$ the frequency that gives higher chloride concentrations. The reason for these differences lies in the different conducting paths present in the system, as discussed in the next section.

The high frequency impedance data were modelled according to the approach described in the literature for similar type of samples [21]. In Fig. 3A the evolution of the impedance spectra with the treatment time is presented. Fig. 3B summarises one example of impedance data together with the corresponding equivalent circuit and a sketch of the two capacitive time constants involved. The $R_{1}$ parameter accounts for the resistivity of the sample, related to the percolating porosity. $R_{e}$ represents the resistance of the electrolyte at both sides of the cementitious membrane. $R_{2}$ is related to the rate of ionic exchange between the pore walls and the electrolyte. $C_{1}$ represents the dielectric capacitance of the solid phase, and $\mathrm{C}_{2}$ that of the double layer at pores walls (occluded or non-percolating pores). The diameter of the capacitive arc corresponds to $\mathrm{R}_{1}$ but two time constants are involved: one in the high frequency domain involving $C_{1}$ and the parallel association of $R_{1}$ and $R_{2}$, and the second one in the low frequency domain, with the remaining resistance and $\mathrm{C}_{2}$. The sketch of both contributions is depicted in Fig. 3B. 
According to Fig. 3B, the time constant associated to the ionic exchange between the solution and pores walls lies in the $\mathrm{kHz}$ range, and thus any current pulse in that frequency domain will activate those regions that remain, as occluded areas in a DC regime. Of course, each frequency will activate only the pore family corresponding to the corresponding specific time constant [22].

The relevant parameter to focus the discussion from now on is $R_{1}$. The evolution of $R_{1}$ has been followed with immersion time to account for the chloride transport [4]. The results are represented in Figure 4 where it can be seen that the percolating resistance, $R_{1}$, is smaller for the $1 \mathrm{kHz}$ frequency, which indicates faster chloride transport, in accordance with the results presented in Fig. 2 where the evolution of the chloride concentration in the downstream compartment is presented.

Figure 3

Figure 4

The continuous increasing of the $R_{1}$ values up to about 35 days is an unexpected result because the ingress of chlorides shall produce an increases the electrolyte conductivity and thus decreasing $R_{1}$ values. The only reasonable interpretation seems to be the blocking of the porosity by Friedel's salt formation, which overcompensates the conductivity increasing. Although this argument will need of further experimental evidence for verification, some support can be derived here either from the physical characterisation data reported later in sections 3.3 and 3.4 , where evidence of the occurrence of structural changes is presented, and from the analytical data reported in Fig. 2, which indicate that the transport of chlorides is not a smooth homogeneous process because of the slope changes noticed.

The shape of the curves in Fig. 4 gives also indirect evidence of the dynamic behaviour of the pore structure. From 12 to 20 days the slope is less than that in the first 10 days, which indicates a kind of ionic concentration increasing that compensates the above mentioned precipitation. This period roughly matches with the excess time lag observed in Fig. 2 for the pulsed current treatments with respect to the $D C$ one. Further, when chlorides start to arrive in the downstream compartment according to Fig. 2, the $R_{1}$ parameter sharply increases (20 to 30 days in Fig. 4), which can be interpreted as due to concentration relaxation of the above mentioned pore solution. Summarising, the transport of chlorides seems to involve a dynamic process of pore blocking and unblocking that comprises a larger fraction of the porosity for the pulsed current treatment. 
After 35 days the increasing volume of the Friedel's salt precipitate can induce mechanical stress with the formation of new ionic paths that justify the observed $R_{1}$ decreasing [23].

\subsection{Speed of sound}

The speed of ultrasonic pulses is currently employed as a non-destructive method to inspect the presence of internal defects in structures. Low-frequency ultrasound (50 kHz) is usually used to characterize large defects (in the $\mathrm{cm}$ range) at large depths inside the structure [24]. However, the use of higher frequencies $(0.5-1 \mathrm{MHz})$ has been demonstrated more suitable for the detection of small size changes or concrete cover degradation [25]. For this reason we have chosen the $0.5 \mathrm{MHz}$ frequency to follow the expected structural transformations, at the micrometre level, occurring during the migration processes.

It is well documented in the literature that the speed of sound increases with density of concrete $[26,27]$ and water saturation of the sample $[28,29]$. Thus, in the present case, with watersaturated samples, it seems reasonable to attribute changes in the speed of sound through the samples to changes occurring in the microstructure due to lixiviation or precipitation of compounds containing chloride.

Figure 5 summarises the normalised pulse transmission time (inverse of the normalised speed of sound) for two sets of experiments, DC and AC $10 \mathrm{kHz}$. Although all initial speeds were about $10^{3}$ $\mathrm{m} . \mathrm{s}^{-1}$, the normalisation with respect to the initial propagation time in each sample was chosen to facilitate the comparison between sets of experiments.

The data presented in figure 5 clearly show the increase of sound speed with the treatment time, which can be related to the precipitation of the Friedel's salt and the corresponding filling of porosity, which is higher for the DC treatment.

Although the scatter of data does not allow to extract detailed information on the precipitation process, the general trend is consistent with the electrochemical data above discussed. The AC treatment seems to be able of mobilising the solution at the pore wall level [30] which hinders the reaction of chlorides to form the Friedel's salt and thus favours the transport.

Figure 5 


\subsection{Mercury intrusion porosimetry}

Figure 6 summarises the MIP results obtained for the different conditions tested. The data presented in Figure $6 \mathrm{~A}$ and $6 \mathrm{C}$ correspond to a single sample. The same applies to Figure $6 \mathrm{~B}$ and $6 \mathrm{C}$; i.e., the label "Reference" refers to the same sample prior to the migration test. After the migration tests, MIP analysis were performed on fractions of each sample taken from the anodic side, cathodic side and the bulk. The results are plotted and identified the same way in Fig. 6A to 6D. A visual comparison of Fig. $6 \mathrm{~A}$ and $6 \mathrm{~B}$ allows to say that the pulsed current treatment (Fig. 6B) induces less microstructural changes than the DC one (Fig. 6A).

A quantitative analysis of the porosity is presented in Figs. $6 \mathrm{C}$ and $6 \mathrm{D}$. As can be easily seem, a refinement of the structure occurs with both treatments, which is consistent with the hypothesis of Friedel's salt precipitation. The pulsed current treatment promotes the development of pores in the $10 \mathrm{~nm}$ range while the $\mathrm{DC}$ treatment affects mainly the $10-100 \mathrm{~nm}$ range. This means that higher density of ionic paths is developed during in the AC treatment, which is in agreement with the higher ionic fluxes recorded (Fig. 2).

Figure 6

\section{CONCLUSIONS}

This study proves that pulsed current enhances chlorides transport rate with respect to traditional DC treatments. In both cases the ingress of chlorides induces microstructural changes involving microstructure refinement.

The results obtained from the impedance spectroscopy and mercury intrusion porosimetry indicate that the fraction of percolating pores is reduced when using pulsed current in comparison with direct current method. Moreover, the use of pulsed current increases the efficiency of ionic transport.

The application of pulsed current is expected to minimise the negative effects in microstructure during DC current treatments as realkalinisation or chloride extraction. 


\section{ACKNOWLEDGEMENTS}

The authors acknowledge the Spanish Ministry of Science and Innovation for funding the project BIA2010-16950

\section{REFERENCES}

[1] Shi X, Xie N, Fortune K, Gong J. Durability of steel reinforced concrete in chloride environments: An overview. Constr Build Mater 2012; 30: 125-38.

[2] Stanish KD, Hooton RD, Thomas MDA. Testing the chloride penetration resistance of concrete: a literature review. Department of Civil Engineering, University of Toronto. Federal Highway Administration (USA), Publication No. FHWA-RD-00-142, 2000.

[3] Castellote M, Andrade C. Round robin test on methods for determining chloride transport parameters in concrete. Mater Struct 2006; 39: 955-90.

[4] Díaz B, Nóvoa XR, Pérez MC. Study of the chloride diffusion in mortar: A new method of determining diffusion coefficients based on impedance measurements. Cem Concr Compos 2006; 28: 237-45.

[5] Sánchez I, Nóvoa XR, de Vera G, Climent MA. Microstructural modifications in Portland cement concrete due to forced ionic migration tests. Study by impedance spectroscopy. Cem Concr Res 2008; 38: 1015-25.

[6] Koleva DA, Hu J, van Breugel K, de Wit JHW, Fraaij ALA. Some advantages of pulse, compared to conventional cathodic protection in reinforced concrete, J Corros Sci Eng 2006; 9: 1-23.

[7] Koleva DA, Guo Z, van Breugel K, de Wit JHW. Conventional and pulse cathodic protection of reinforced concrete: Electrochemical behavior of the steel reinforcement after corrosion and protection. Mater Corros 2009; 60: 344-54.

[8] Fajardo G, Escadeillas G, Arliguie G. Electrochemical chloride extraction (ECE) from steelreinforced concrete specimens contaminated by "artificial" sea-water. Corros Sci 2006; 48: 11025. 
[9] Yeih W, Chang JJ. A study on the efficiency of electrochemical realkalisation of carbonated concrete. Constr Build Mater 2005; 19: 516-24.

[10] Yodsudjai W, Saelim W. Influences of Electric Potential and Electrolyte on Electrochemical Chloride Removal in Reinforced Concrete. J Mater Civ Eng 2013, in press. (doi: 10.1061/(ASCE)MT.1943-5533.0000777).

[11] Orellan JC, Escadeillas G, Arliguie G. Electrochemical chloride extraction: efficiency and side effects. Cem Concr Res 2004; 34: 227-34.

[12] Siegwart M, Lyness JF, McFarland BJ. Change of pore size in concrete due to electrochemical chloride extraction and possible implications for the migration of ions. Cem Concr Res 2003; 33: 1211-21.

[13] Guo YX, Gong JX. Degradation of bond between steel bar and freeze-thaw concrete after electrochemical chloride extraction. J. Central South University of Technol. (English Edition) 2010; 17: 388-93.

[14] Cabeza M, Merino P, Nóvoa XR, Sánchez I. Electrical effects generated by mechanical loading of hardened Portland cement paste. Cem Concr Compos 2003; 25: 351-56.

[15] Urbanski JP, Thorsen T. Fast ac electro-osmotic micropumps with nonplanar electrodes. App Phys Lett 2006; 89: 143508.

[16] Bazant MZ, Squires TM. Induced-Charge Electrokinetic Phenomena: Theory and Microfluidic Applications. Phys Rev Lett 2004; 92: 066101.

[17] Gani MSJ. Cement and Concrete. Chapman\&Hall, London; 1997.

[18] ASTM Standard C 1202-97. Standard test method for electrical indication of concrete's ability to resist chloride ion penetration. Annual Book of ASTM Standard Section 4, vol. 04.02, 2000.

[19] Díaz B, Freire L, Nóvoa XR, Puga B, Vivier V. Resistivity of cementitious materials measured in diaphragm migration cells: The effect of the experimental set-up. Cem Concr Res 2010; 40: 146570. 
[20] Koleva DA, Copuroglu O, van Breugel K, Ye G, de Wit JHW. Electrical resistivity and microstructural properties of concrete materials in conditions of current flow. Cem. Concr. Compos 2008; 30: 731-44.

[21] Cabeza M, Merino P, Miranda A, Nóvoa XR, Sánchez I. Impedance spectroscopy study of hardened Portland cement paste. Cem Concr Res 2002; 32: 881-91.

[22] Alonso C, Andrade C, Keddam M, Nóvoa XR, Takenouti H. Study of the dielectric characteristics of cement paste. Mater Sci Forum 1998; 289-292: 15-28

[23] Díaz B, Freire L, Merino P, Nóvoa XR, Pérez MC. Impedance spectroscopy study of saturated mortar samples. Electrochim Acta 2008; 53: 7549-555.

[24] Krause M, Bärmann M, Frielinghaus R, Kretzschmar F, Kroggel O, Langenberg KJ, Maierhofer C, Müller W, Neisecke J, Schickert M, Schmitz V, Wiggenhauser H, Wollbold F. Comparison of pulseecho methods for testing concrete. NDT\&E Internat., 1997; 30: 195-204.

[25] Ould Naffa S, Goueygou M, Piwakowski B, Buyle-Bodin F. Detection of chemical damage in concrete using ultrasound. Ultrasonics 2002; 40: 247-51.

[26] Hernández MG, Izquierdo MAG, Ibáñez A, Anaya JJ, Ullate LG. Porosity estimation of concrete by ultrasonic NDE. Ultrasonics 2000; 38: 531-33.

[27] Benouisa A, Grini A. Estimation of concrete's porosity by ultrasounds. Phys Proc 2011; 21: 53-8.

[28] Ohdaira E, Masuzawa N. Water content and its effect on ultrasound propagation in concrete: the possibility of NDE. Ultrasonics 2000; 38: 546-52.

[29] Lafhaj Z, Goueygou M, Djerbi A, Kaczmarek M. Correlation between porosity, permeability and ultrasonic parameters of mortar with variable water/cement ratio and water content. Cem Conc Res 2006; 36: 625-33.

[30] Nóvoa XR. Impedance spectroscopy on hardened Portland cement paste - a review. Bulg Chem Comm 2004; 36: 13-9. 


\section{FIGURES}

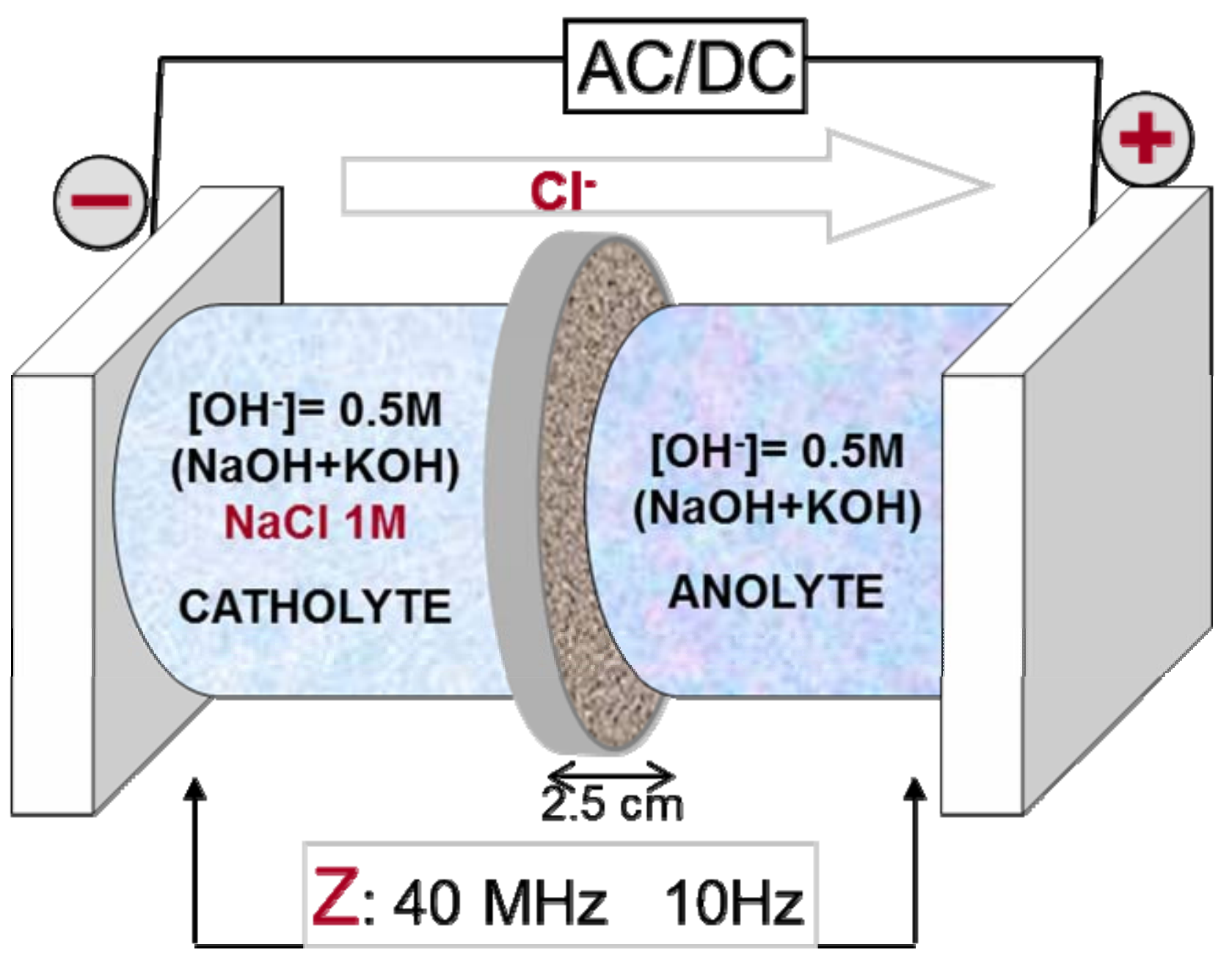

Figure 1. Schematic view of the experimental permeation cell employed. 


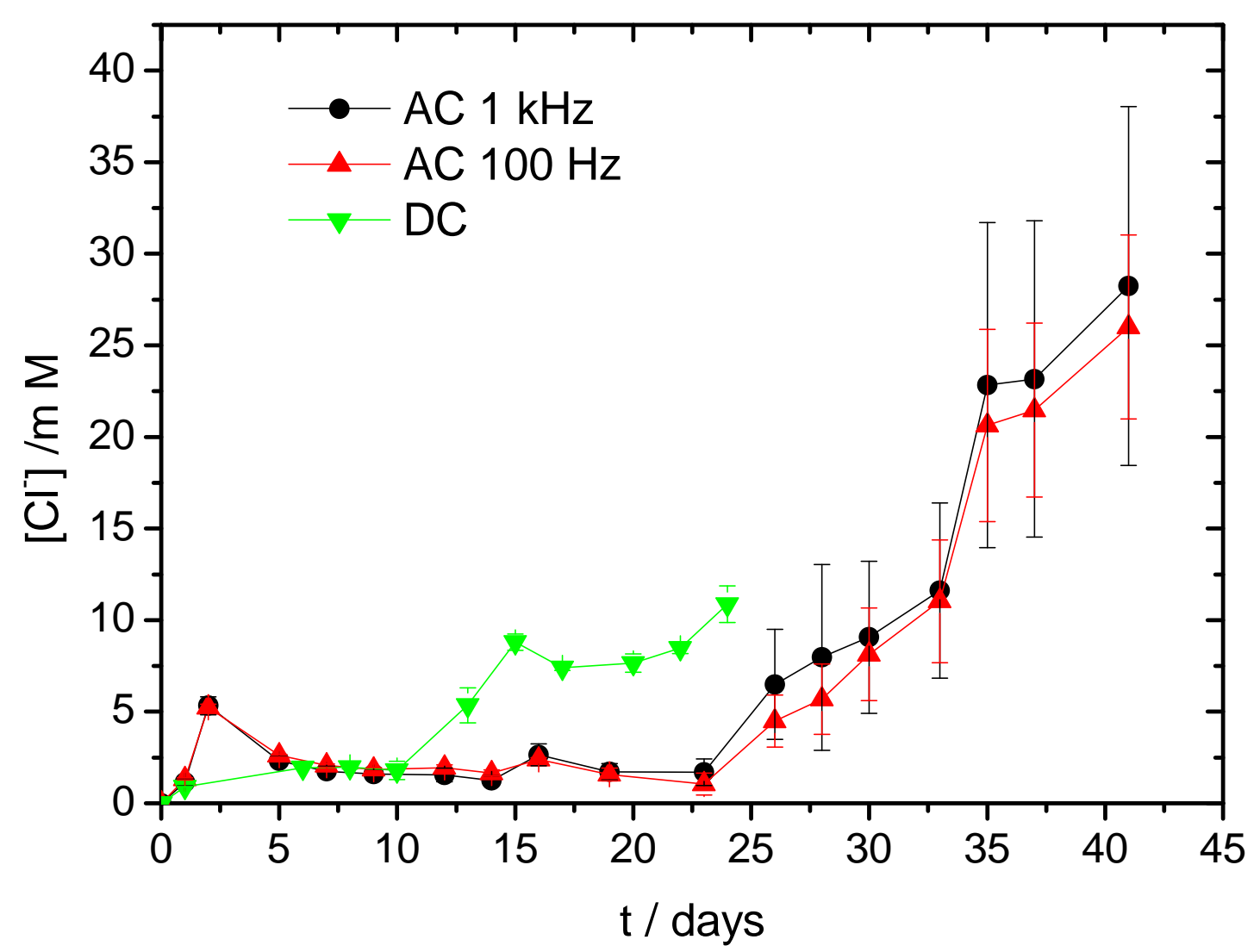

Figure 2. Evolution of the chloride concentration in the anodic compartment during the testing period for the different current regimes. The results at $10 \mathrm{kHz}$ are essentially the same than at $1 \mathrm{kHz}$ and are omitted in the figure. The error bars represent the average of three replicas. 

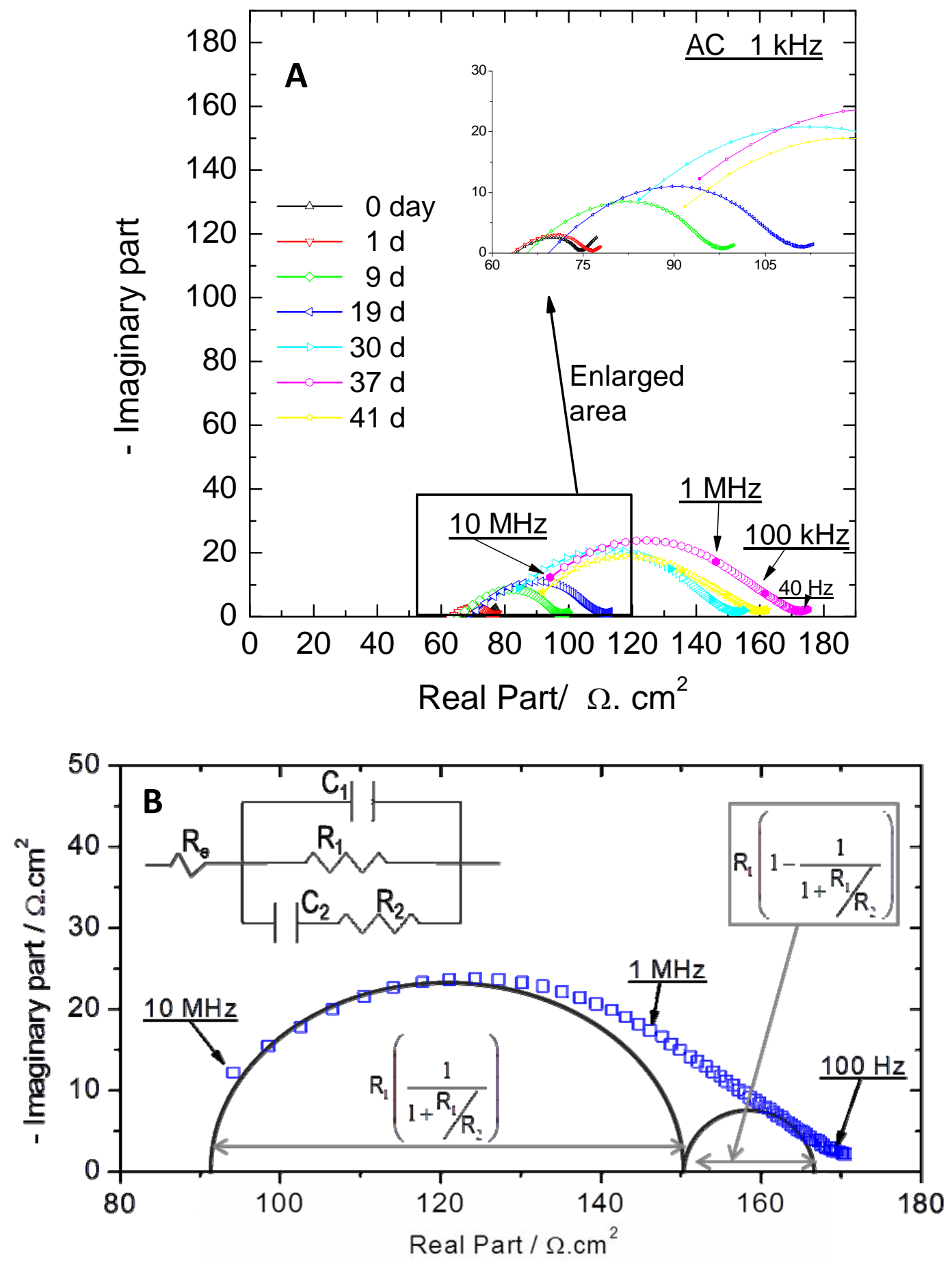

Figure 3. A) Evolution of the sample's impedance spectra with treatment time for one of the tested samples under pulsed regime $(1 \mathrm{kHz})$.

B) Detail of the 37-days measurement showing the equivalent circuit employed for modelling and a sketch of the two time constants involved. 


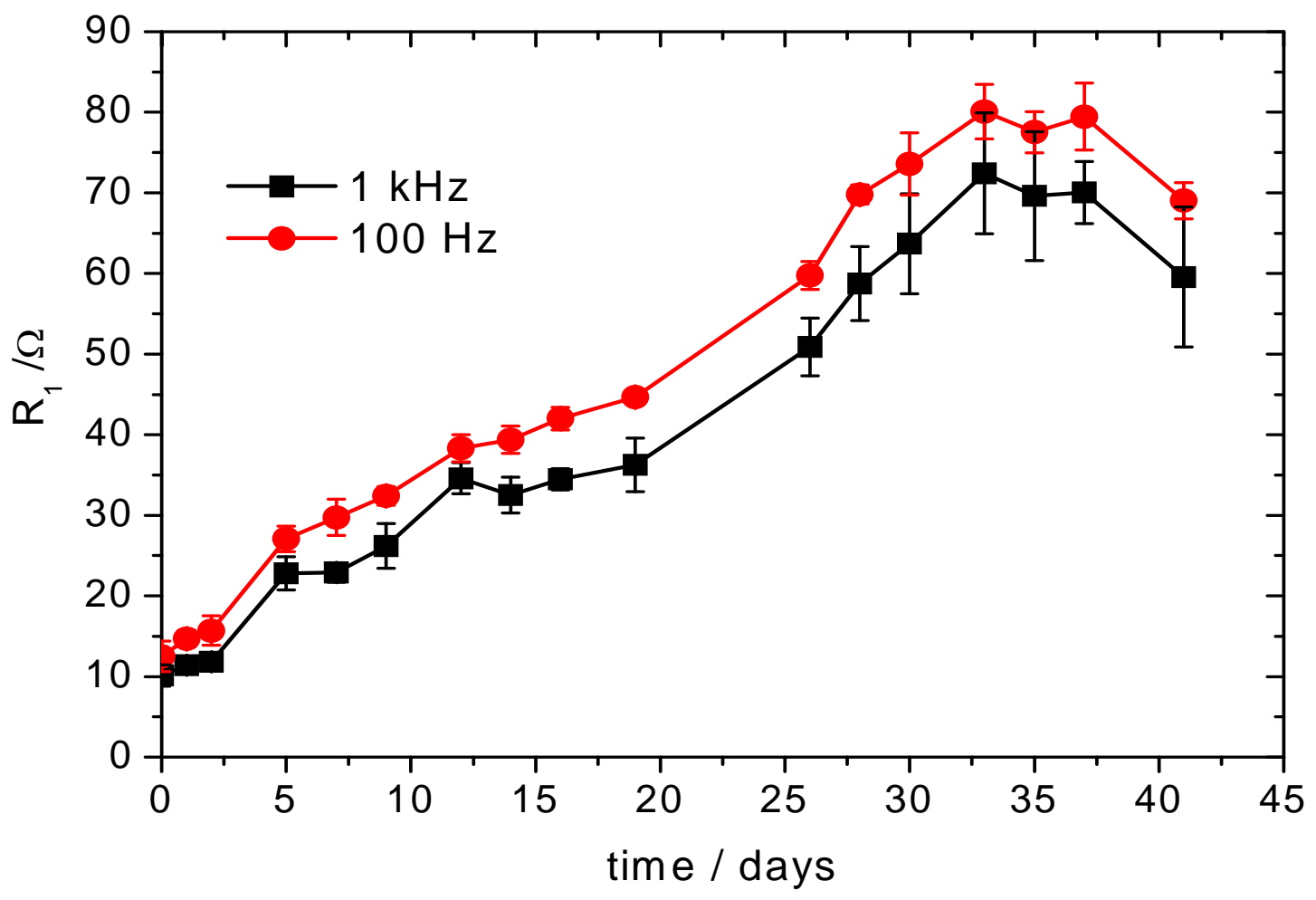

Figure 4. Evolution of the $\mathrm{R}_{1}$ parameter (see Fig. 3) for the $1 \mathrm{kHz}$ and $100 \mathrm{~Hz}$ migration. 


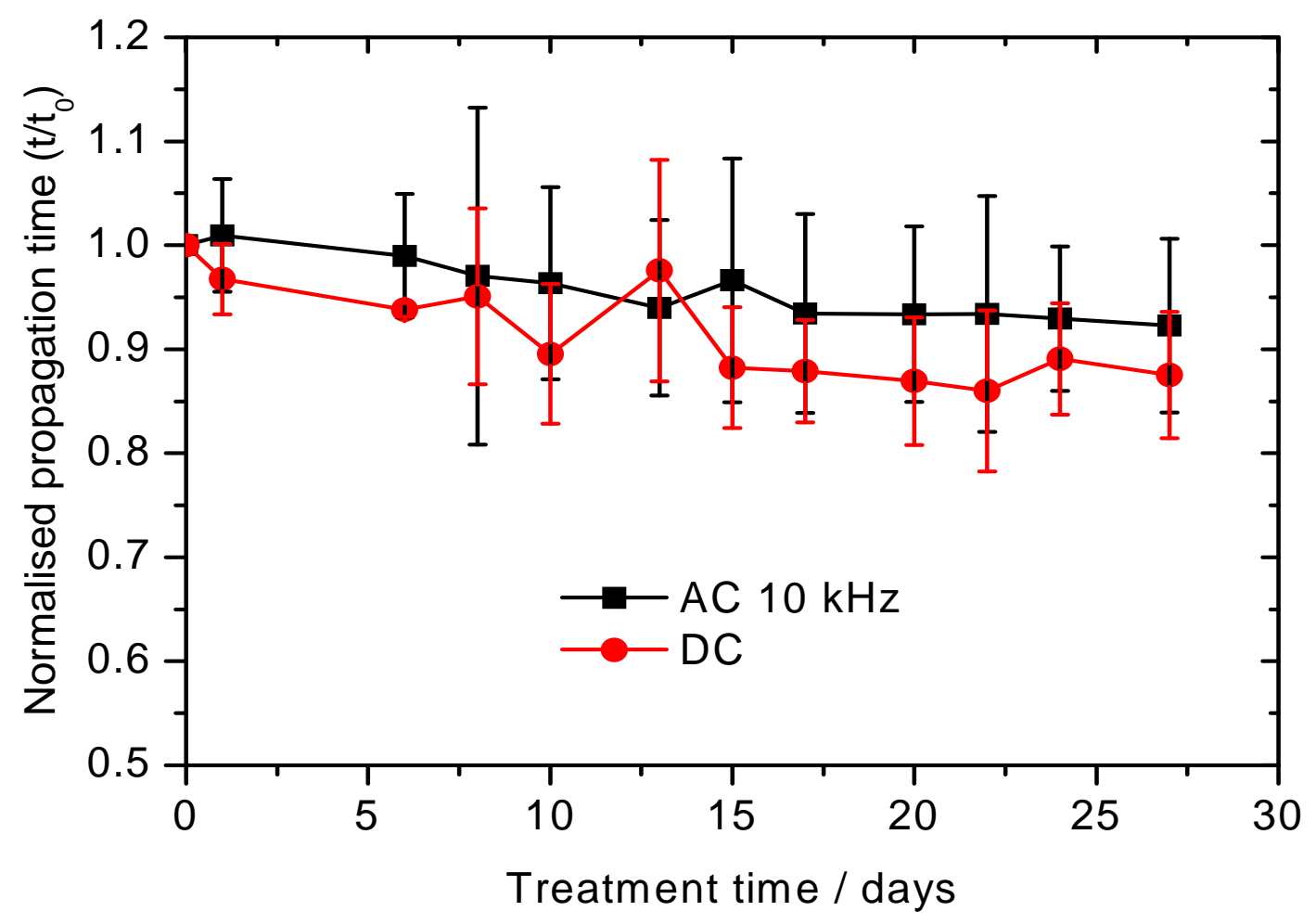

Figure 5. Evolution of the propagation time in the studied samples with the test duration. The propagation time, $t$, was normalised with respect to the initial propagation time, $t_{0}$. The initial ultrasound speed was around $10^{3} \mathrm{~m} \cdot \mathrm{s}^{-1}$ for unsaturated samples and twice that value for water saturated ones. 

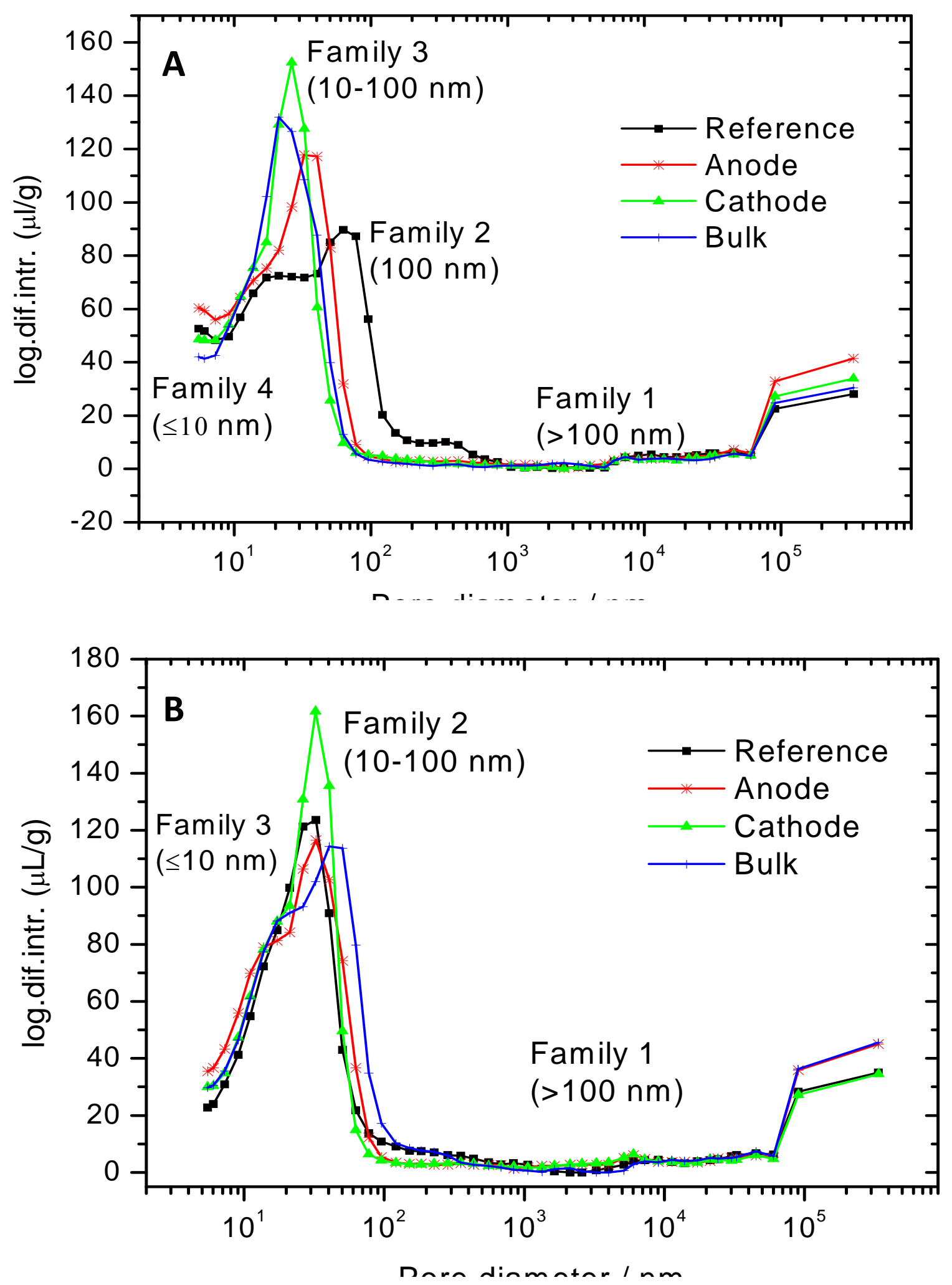

Figure 6. Mercury intrusion porosimetry results split in four sets: Reference (prior testing), Anode (sample, anode side), Cathode (sample, cathode side), Bulk (sample, centre) for DC treatment $\mathrm{A}$ ), and $10 \mathrm{kHz}$ treatment $\mathrm{B}$ ). The corresponding relative contribution to total 
porosity of the various pore families is represented in Figs. C) and D). The total porosity was $15 \% \pm 2 \%$.
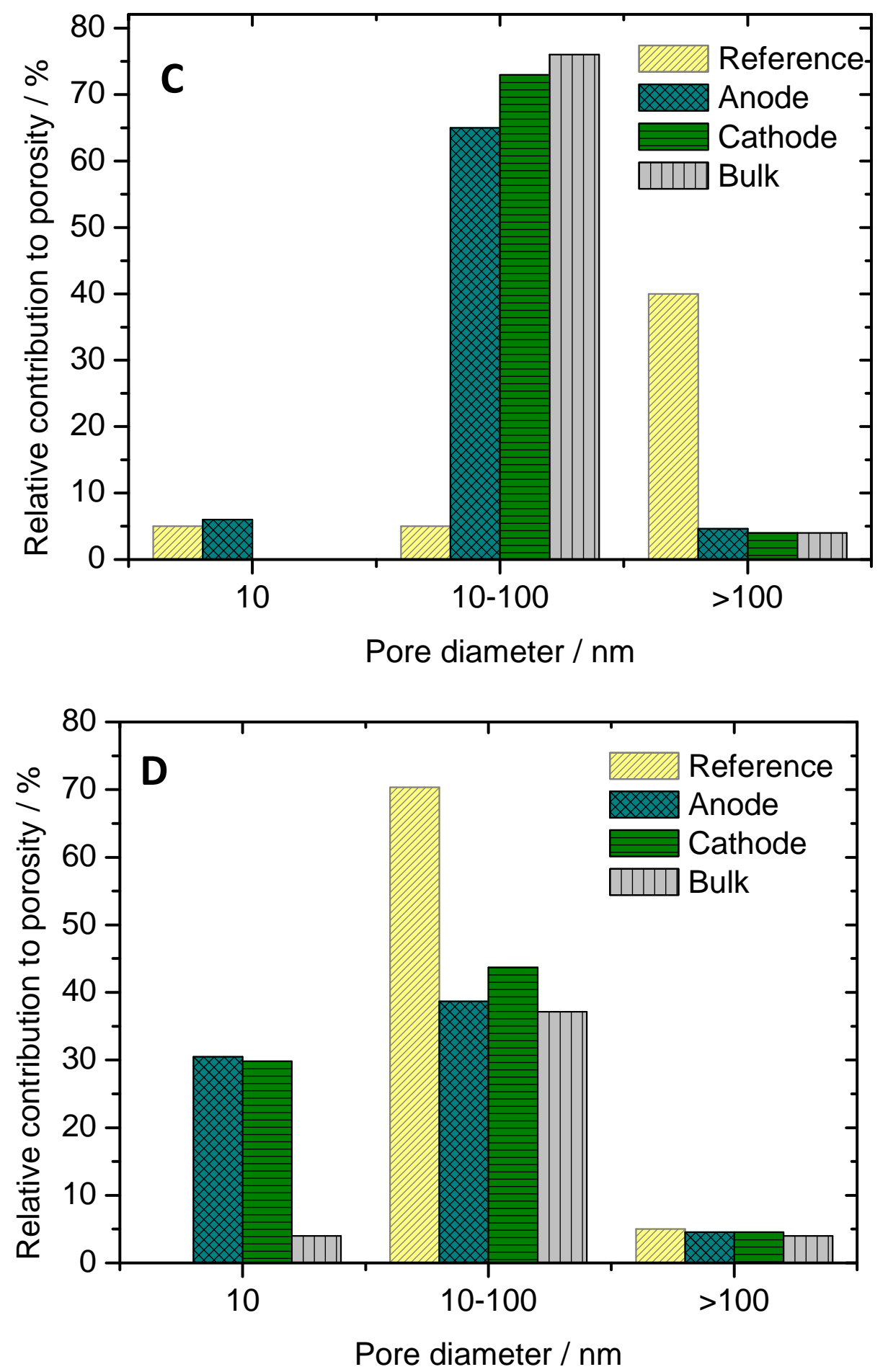

Figure 6. Mercury intrusion porosimetry results split in four sets: Reference (prior testing), Anode (sample, anode side), Cathode (sample, cathode side), Bulk (sample, centre) for DC treatment $\mathrm{A}$ ), and $10 \mathrm{kHz}$ treatment $\mathrm{B}$ ). The corresponding relative contribution to total 
porosity of the various pore families is represented in Figs. C) and D). The total porosity was $15 \% \pm 2 \%$. 